\title{
Book review: Mining and Quarrying in the Ancient Andes: Sociopolitical, Economic and Symbolic Dimensions
}

\author{
Robert A. F. F.-X. Ixer \\ Institute of Archaeology, University College London, 31-34 Gordon Square, WC1H OPY, London, U.K. \\ Email: r.ixer@btinternet.com
}

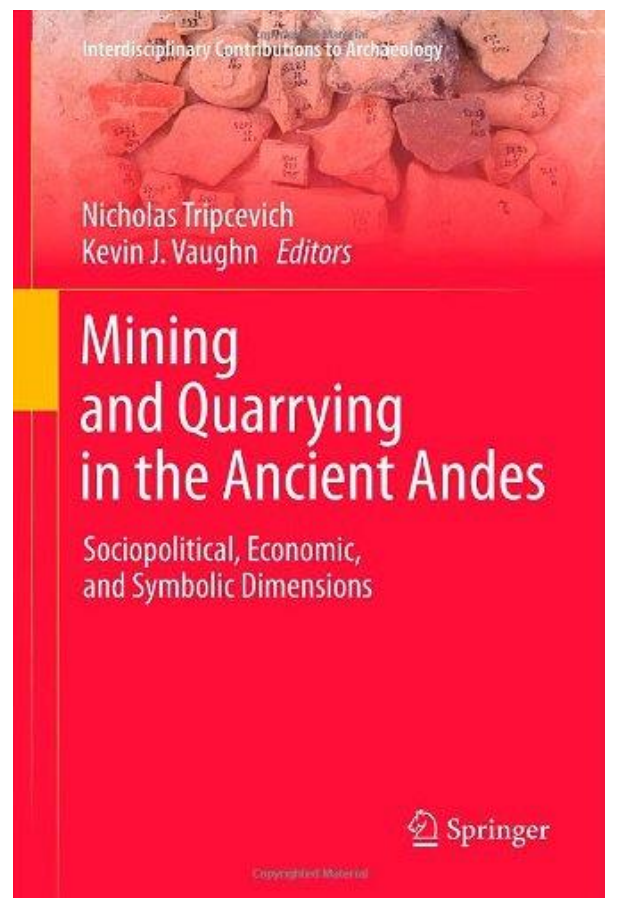

Mining and Quarrying in the Ancient Andes: Sociopolitical, Economic and Symbolic Dimensions edited by Nicholas Tripcevich and Kevin J. Vaughn

Springer, 2013, pp. 353. ISBN 978-1-4614-5199-0

http://www.springer.com/us/book/9781461451990

The high Andes is one of the world's great metallogenic provinces having produced and still providing very significant amounts of copper, silver, tin and historically, of course, gold. The Andean pre-Colombian metal mining tradition, clearly isolated from that of Eurasia, provides independent alternative examples of early, non-mechanised mining and its less tangible 'sociopolitical, economic and symbolic dimensions'.

In the introduction, the editors state the theme of the volume, namely "Prehispanic

Published by the School of History, Classics and Archaeology, University of Edinburgh ISSN: 2055-0472. URL: http://journals.ed.ac.uk/lithicstudies/

This work is licensed under a Creative Commons Attribution 2.5 UK: Scotland License. 
mining is aesthetic, utilitarian and religious" restricting the chapters to recording the evidence for hard rock mining or quarrying and initial processing and transport of the raw materials, less tangible attributes associated with the winning of these raw materials, the "symbolic dimension" of the mines and quarries and their products, ending with broader discussions of "mining within Pre-Colombian societies".

Six chapters are on non-metallic ores, including building stone, essentially sandstone and andesite, clay and tempering materials, rock salt and iron pigments, six chapters are on metallic ores, copper, gold, silver, a little mercury, and a final two chapters review the earlier ones. Temporally, the chapters range from the early Holocene to the end of the Inka culture or early Colonial period with some reliance on Post-Colombian and modern ethnographic data. Spatially, they range from southern Ecuador to central Chile but mainly concentrate on an area from Lake Titicaca moving west-northwest to south of Lima. Many chapters show the difficulty in dating the sites and their buildings, partly because of later Colonial to postColonial exploitation, partly due to the lack of datable inorganic finds and partly because of the lack of organic matter to give absolute dates.

Ogden reviews Inka stonework and concludes that "understanding how the Incas quarried $[\ldots]$ and the nature of imperial architecture [...] is integral to the broader questions of understanding how the Incas carried out their Imperial enterprise". Janusek et al relook at the use and provenance of sandstone and andesite by the Tiwanaku (one of a number of papers centred on Lake Titicaca) and come to similar thoughts about Pre-Inka stonework. Other chapters in this section discuss, post-Colonial and modern rock salt mining, red and orange pigment mining in the Archaic period on the north coast of Chile (by very small settled and unsettled communities), haematite mining and pottery production in the Nasca during the Early Intermediate period, and finally clay and temper acquisition in the Lake Titicaca Basin.

Brooks et al. discuss mercury and precious metal amalgamation in the Andes using present day and historical practices to interpret the chemistry of a large number of preHispanic artefacts. Schultze describes and reviews the evidence for the very long-lived metal (silver and copper mainly) exploitation and lithic quarrying around Puno (Lake Titicaca). Salazar et al, in a well-argued chapter, show the material and architectural evidence for the technological, ritual and socio-political control by the Inka of copper mining in the Atacama although the 'technology' was more in the manner of industrialisation or economies of scale rather than new ways of winning and processing copper ores. Van Gijseghem et al. explore mines as sacred huacas and mining as "a symbolically charged act". This chapter is in marked contrast to Reindel et al. whose research on mining archaeology in the Nasca-Palpa region from Archaic to the Late Intermediate period uses their data to illuminate the broader issue of changing settlement patterns. This is the most rewarding data chapter, an example of how this work should be done, coming closest to the pattern of balanced research that Shimada advocates.

The last two chapters are both a summation and critique of the earlier ones. Burger makes a very timely plea with regard to the need for good field work now. Shimada makes a similar point; his critique, concentrating on the metal mining chapters proposes a "caution to ethnohistorical information and insights". Both caution against the uncritical use of the Inka as a model for earlier exploitation but the shadow of the Inka is cast throughout the volume.

This volume is timely and welcome; the chapters are full of good ideas, some monumental speculation and have that indefinable American, more anthropological feel. As with the Andes themselves the discovery and exploitation of the raw materials in this volume (its data) will foster the search for new riches but its main, often subliminal, sometimes unintentional, message must be that — finding El Dorado needs planned teamwork from the outset. 